\title{
Clear-Air Turbulence (CAT) Identification with X-Band Dual Polarimetric Radar Based on Bayesian Approach
}

\author{
Jianli Ma, Li Luo *, Mingxuan Chen and Siteng Li \\ Institute of Urban Meteorology (IUM), Beijing 100089, China; jlma@ium.cn (J.M.); mxchen@ium.cn (M.C.); \\ stli@ium.cn (S.L.) \\ * Correspondence: lluo@ium.cn
}

Citation: Ma, J.; Luo, L.; Chen, M.; Li, S. Clear-Air Turbulence (CAT) Identification with X-Band Dual Polarimetric Radar Based on Bayesian Approach. Atmosphere 2021, 12, 1691. https://doi.org/10.3390/ atmos12121691

Academic Editor: Merhala Thurai and Jimy Dudhia

Received: 29 September 2021 Accepted: 1 December 2021 Published: 17 December 2021

Publisher's Note: MDPI stays neutral with regard to jurisdictional claims in published maps and institutional affiliations.

Copyright: (C) 2021 by the authors. Licensee MDPI, Basel, Switzerland. This article is an open access article distributed under the terms and conditions of the Creative Commons Attribution (CC BY) license (https:// creativecommons.org/licenses/by/ $4.0 /)$.

\begin{abstract}
The echo of weather radar is seriously disturbed by clear-air turbulence echo (CAT) which needs identifying and eliminating to improve the data quality of weather radar. Using the data observed with the five X-band dual polarimetric radars in Changping, Fangshan, Miyun, Shunyi, and Tongzhou, Beijing in 2018, the probability density distribution (PDD) of the horizontal texture of four radar moments reflectively factor $\left(Z_{H}\right)$, differential reflectivity $\left(Z_{D R}\right)$, correlation coefficient $\left(\rho_{\mathrm{HV}}\right)$, differential propagation phase shift $\left(\Phi_{\mathrm{DP}}\right)$, and then the CAT is identified and removed using Bayesian method. The results show that the radar data can be effectively improved after the CAT has been eliminated, which include: (1) the removal rate of CAT is more than $98.2 \%$ in the analyzed cases. (2) In the area with high-frequency distribution of CAT, the CAT can be effectively suppressed; in the area with low-frequency distribution, some weather echo in the edge with $\mathrm{SNR}<15 \mathrm{~dB}$ may be mistakenly identified as CAT, but the proportion of meteorological echoes to the total echoes is more than $85 \%$, which indicate that the error rate is very low and does not affect the radar operation.
\end{abstract}

Keywords: clear-air turbulence; dual-polarization X-band weather radar; Bayesian method

\section{Introduction}

X-band dual-polarization radar (hereinafter X-POL) is applied to monitor small scale basins weather in mountainous regions and urban areas [1,2], and it can be a cost-effective system for filling up gaps in existing national radar networks [3]. Beijing, the capital of China, is often suffering from medium- and small-scale disastrous weather, in order to improve the ability of monitoring and warning for weather disaster, Beijing Meteorological Bureau had built five X-POL radars by the year end of 2018.

Clear air turbulence echoes (hereafter CATs) can be observed by X-band radar [4-6]. The CATs of five X-POLs are source of contaminations for radar precipitation estimations, it is need to remove CATs and only retain the precipitation echoes. However, CAT is just one type of echoes observed by X-POL, the others are including, (1) ground clutter (GC), (2) anomalous propagation (AP), (3) biological echo (such as bird or insect echo), (4) meteorological echoes (ME). In order to identify and eliminate CAT, it is necessary to establish CAT dataset for acquiring identification model.

Clear-air echoes(hereafter CAEs) are detected by X-POLs in sunny day, CAEs is usually composed of two types, one is the biological echo, which is caused by the scattering of insects or birds, the biological echoes are mainly dotted echoes, bands, etc., which will have an impact on Doppler velocity [7,8], and the other is the CAT, which is caused by fluctuations of refractive index, CATs are mainly layered, annular, wavy, etc. [9]. CAT has the characteristics of diurnal and seasonal variation [10]. Some machine learning methods have been applied to identify CAT, with the emergence and development of artificial intelligence algorithms [11,12]. These above methods have a certain filtering effect on the CAE of Doppler weather radar, however, there are rare studies carried out for dual polarization radar. 
In this study, a Bayes classifier (BC) to identify CAT was developed and demonstrated using data from the Beijing X-POLs. The BC is assessed against an existing method (a fuzzy logic classifier, hereafter FLC) for CAT identification. This paper is organized as follows: Section 2 describes the radar data and introduces the Bayesian approach methodology. A case study and the comparison results between the BC and FLC are presented in Section 3. Section 4 provides the discussion and conclusion.

\section{Data and Methods}

\subsection{Instruments and Data}

Five X-POL radars in Beijing were located in Changping (CP), Fangshan (FS), Miyun (MY), Shunyi (SY) and Tongzhou (TZ) districts. Figure 1 shows the sample pictures of the five radars and their geographical location are displayed in Figure 2, the radius distance of the circle is $75 \mathrm{Km}$. The performance parameters of each radar are shown in Table 1. Five radars operate mode is VCP 21. Nine elevation volume scans were performed every $3 \mathrm{~min}$ $\left(0.5^{\circ}, 1.5^{\circ}, 2.4^{\circ}, 3.3^{\circ}, 4.3^{\circ}, 6^{\circ}, 9.9^{\circ}, 14.6^{\circ}, 19.5^{\circ}\right)$.

Table 1. Specification of X-POL radar.

\begin{tabular}{cc}
\hline Transmitting Frequency & $\mathbf{9 . 3 - 9 . 5 ~ G H z ~ ( X - B a n d )}$ \\
\hline Wavelength & $3.2 \mathrm{~cm}$ \\
Peak power & $70 \mathrm{kw}$ \\
Average Power & $112 \mathrm{w}$ \\
Max. Duty Cycle & $0.16 \%$ \\
Antenna type (diameter) & Front-fed parabolic $(2.4 \mathrm{~m})$ \\
3-dB beam width & $0.94^{\circ}$ \\
Polarization & Dual linear, $\mathrm{H}$ and V channel \\
Range resolution & $75 \mathrm{~m}$ \\
Maximum pulse width & $1 \mu \mathrm{s}$ \\
Variables & $\mathrm{Z}, \mathrm{V}, \mathrm{W}, \mathrm{Z}_{\mathrm{DR}}, \rho_{\mathrm{HV}}, \mathrm{K}_{\mathrm{DP}}, \Phi_{\mathrm{DP}}, \mathrm{SNR}$ \\
\hline
\end{tabular}

CAEs and precipitation dataset were collected by using observation data of X-POL in 2018, in which CAEs using sunny detection data and precipitation echoes using rainy detection data. In data processing, GC and AP were firstly eliminated using the method proposed by Rico et al. [13] to ensure that the remaining echoes were CAEs in sunny day or precipitation echoes in rainy day. Biological targets or bird migration are removed by the way used by Lakshmanan et al. [14]. so after GC/AP removing, the rest of echoes were CATs in sunny day, and meteorological echoes (hereafter MEs) in rainy day, then CAT dataset and ME dataset have been acquired. 


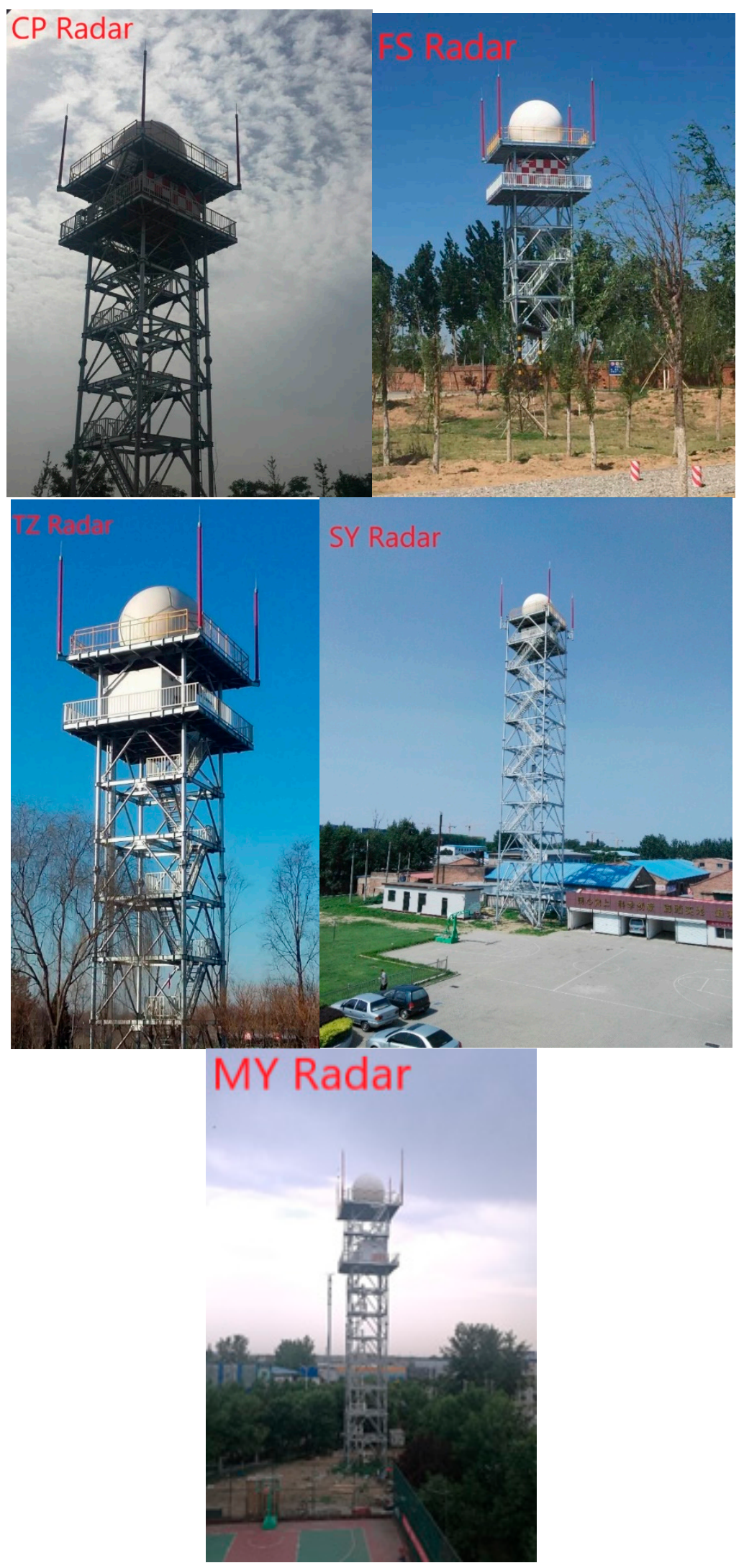

Figure 1. Installation of Beijing X-band dual-polarization radars(X-POL). The letter symbols, such as " $\mathrm{CP}^{\prime}$, correspond to the name of various radars. More information about the deployment of the five radars can be found in Table 1 . 


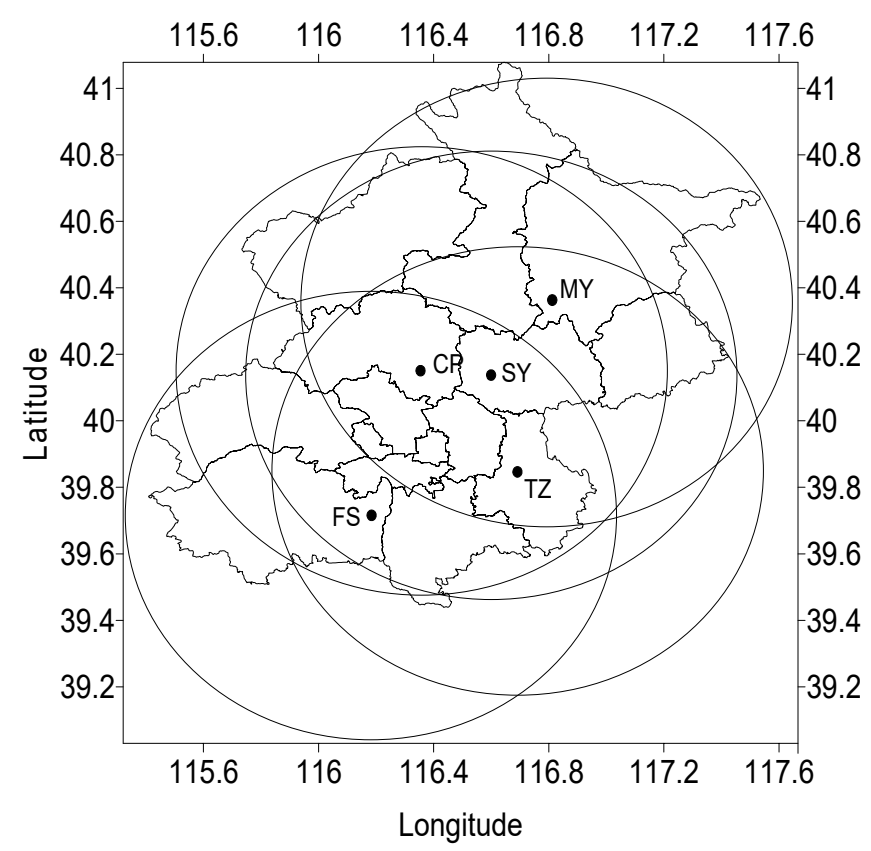

Figure 2. The layout of the dual-polarization $X$-band radars ( $75 \mathrm{~km}$ range rings). The letter symbols, such as "CP", correspond to the name of various radars.

\subsection{Methodology}

2.2.1. Bayesian Approach for the Identification of CATs

The standard deviation of X-POL radar polarization parameters is expressed as follows:

$$
S d\left(x_{C}\right)=\sqrt{\sum_{i=C-N / 2}^{C-N / 2}\left(x_{i}-\bar{x}\right)^{2} / N}
$$

Here, the $C$ is the gate number at which the $S d$ is calculated. The $i$ indicates the gate number. $N$ denotes the number of radial range bins selected with $x_{C}$ as the center, and $N$ is 7 in this study, $\bar{x}$ is the average value of $N$ adjacent range bins. $\mathrm{Sd}(\mathrm{Z})$, $\mathrm{Sd}\left(\mathrm{Z}_{\mathrm{DR}}\right), \mathrm{Sd}\left(\rho_{\mathrm{HV}}\right)$ and $\mathrm{Sd}\left(\Phi_{\mathrm{DP}}\right)$ combine to form radar observation discriminant vector $y=\left(S d(Z), S d\left(Z_{d R}\right), S d\left(\rho_{H V}\right), S d\left(\phi_{d P}\right)\right)$. After removing GC/AP for a volume scan data, the remaining echoes are including ME and CAT.The observation vector $y$ is identified as CAT, if $p(\mathrm{CAT} \mid \boldsymbol{y})>p(\mathrm{ME} \mid \boldsymbol{y})$, here, $p$ is probability density [15]:

$$
p\left(C_{i} \mid y\right)=\frac{p\left(y \mid C_{i}\right) p\left(C_{i}\right)}{p(y)}
$$

where $C_{i}=\mathrm{ME}$ and CAT. $p(y)$ is the probability of the vector $y, p(y)$ is the same value for calculation $p(\mathrm{CAT} \mid \boldsymbol{y})$ and $p(\mathrm{ME} \mid \boldsymbol{y})$, so it can be regarded as a constant $\mathrm{K}, p(\boldsymbol{y}) \equiv K$, assuming that the probabilities of ME and CAT are the same, i.e., $p(\mathrm{CAT})=p(\mathrm{ME})=1 / 2$, so $p\left(C_{i} \mid \boldsymbol{y}\right)$ is proportional to $p\left(y \mid C_{i}\right) p\left(C_{i}\right)$, then Formula (2) can be expressed as:

$$
p\left(C_{i} \mid y\right)=\frac{1}{2 K} p\left(y \mid C_{i}\right)
$$

So, $p\left(C_{i} \mid y\right)$ value depends on the value of $p\left(y \mid C_{i}\right)$. Based on the assumption that categories are independent of each other in simple Bayesian judgment, the conditional probability density can be further decomposed into:

$$
\begin{aligned}
& p\left(y \mid C_{i}\right)=p\left(\operatorname{Sd}(Z), S d\left(Z_{d R}\right), S d\left(\rho_{H V}\right), S d\left(\phi_{d P}\right) \mid C_{i}\right) \\
= & p\left(\operatorname{Sd}(Z) \mid C_{i}\right) p\left(\operatorname{Sd}\left(Z_{d R}\right) \mid C_{i}\right) p\left(\operatorname{Sd}\left(\rho_{H V}\right) \mid C_{i}\right) p\left(\operatorname{Sd}\left(\phi_{d P}\right) \mid C_{i}\right)
\end{aligned}
$$


For CAT, the Equation (1) can be expressed as:

$$
p(C A T \mid y)=\frac{1}{2 K} p(S d(Z) \mid C A T) p\left(S d\left(Z_{d R}\right) \mid C A T\right) p\left(S d\left(\rho_{H V}\right) \mid C A T\right) p\left(S d\left(\phi_{d P}\right) \mid C A T\right)
$$

For ME, Similarly, the Equation (1) can be expressed as:

$$
p(M E \mid y)=\frac{1}{2 K} p(S d(Z) \mid M E) p\left(S d\left(Z_{d R}\right) \mid M E\right) p\left(S d\left(\rho_{H V}\right) \mid M E\right) p\left(S d\left(\phi_{d P}\right) \mid M E\right)
$$

So the problem is transformed into acquiring the probability density distribution of parameters for $\mathrm{Sd}(\mathrm{Z}), \mathrm{Sd}\left(\mathrm{Z}_{\mathrm{DR}}\right), \mathrm{Sd}\left(\rho_{\mathrm{HV}}\right)$ and $\mathrm{Sd}\left(\Phi_{\mathrm{DP}}\right)$ (hereinafter PDDs). For CAT dataset, it will acquire PDDs of CAT; for ME dataset, it will acquire PDDs of ME. To a certain a range bin' values for $\mathrm{Sd}(\mathrm{Z}), \mathrm{Sd}\left(\mathrm{Z}_{\mathrm{DR}}\right), \mathrm{Sd}\left(\rho_{\mathrm{HV}}\right)$ and $\mathrm{Sd}\left(\Phi_{\mathrm{DP}}\right)$, it is easy to acquire the probability of $p(\mathrm{Sd}(\mathrm{Z}) \mid C A T), p\left(\mathrm{Sd}\left(\mathrm{Z}_{\mathrm{DR}}\right) \mid C A T\right), p\left(\mathrm{Sd}\left(\rho_{\mathrm{HV}}\right) \mid C A T\right)$ and $p\left(\mathrm{Sd}\left(\Phi_{\mathrm{DP}}\right) \mid C A T\right)$ by using PDDs of CAT, $p(C A T \mid y)$ can be acquired by Equation (5). The probability of $p(\mathrm{Sd}(\mathrm{Z}) \mid M E), p\left(\mathrm{Sd}\left(\mathrm{Z}_{\mathrm{DR}}\right) \mid M E\right), p\left(\mathrm{Sd}\left(\rho_{\mathrm{HV}}\right) \mid M E\right)$ and $p\left(\mathrm{Sd}\left(\Phi_{\mathrm{DP}}\right) \mid M E\right)$ can be acquired by using PDDs of ME, then $p(M E \mid \boldsymbol{y})$ can be obtained by Equation (6). if $p(C A T \mid \boldsymbol{y})>p(M E \mid \boldsymbol{y})$, the echo of this range bin will be distinguished as CAT, otherwise, is ME.

\subsubsection{The Prior Distribution of Polarimetric Parameters}

Using CAT and ME dataset collected in 2018 to calculate the prior distribution of polarimetric parameters. Among the five radars, the prior probability density distribution of polarimetric parameters for CATs using the data from the plan position indicator (PPI) scans at $0.5^{\circ}$ and $1.5^{\circ}$ elevation angle, and the prior density distribution of ME radar parameters using the data from the $>4.3^{\circ}$ PPIs and $50 \mathrm{~km}$ away from the radar, to prevent interference from the near-surface non-meteorological echoes.

Figure 3 shows the probability density distribution (PDD) of texture features of radar parameters obtained from the five radars during 2018. The overlap area of the PDD of the ME and CAT of $\operatorname{Sd}\left(Z_{\mathrm{DR}}\right), \operatorname{Sd}\left(\rho_{\mathrm{HV}}\right)$, and $\operatorname{Sd}\left(\Phi_{\mathrm{DP}}\right)$ is small, which is helpful to distinguish the CATs and MEs. For each parameter, the width of ME PDD is narrower than that of CAT, and the most $\mathrm{Sd}(\mathrm{Z})$ values of $\mathrm{ME}$ are less than $4 \mathrm{dBZ}, \mathrm{Sd}\left(\mathrm{Z}_{\mathrm{DR}}\right)$ values are less than $2 \mathrm{~dB}$, $\operatorname{Sd}\left(\Phi_{\mathrm{DP}}\right)$ values are less than $10^{\circ}$ and $\operatorname{Sd}\left(\rho_{\mathrm{HV}}\right)$ values are less than 0.02 . When a certain range bin parameters for $\mathrm{Sd}(\mathrm{Z}), \mathrm{Sd}\left(\mathrm{Z}_{\mathrm{DR}}\right), \mathrm{Sd}\left(\rho_{\mathrm{HV}}\right)$, and $\mathrm{Sd}\left(\Phi_{\mathrm{DP}}\right)$ are used in Formula (4), If the ME PDD is used in Figure 3, the probability of $\mathrm{ME}\left(\mathrm{P}_{\mathrm{ME}}\right)$ is obtained, If the CAT PDD is used in Figure 3, the probability of CAT $\left(\mathrm{P}_{\mathrm{CAT}}\right)$ is obtained, if $\mathrm{P}_{\mathrm{CAT}}>\mathrm{P}_{\mathrm{ME}}$, the echo of this bin can be distinguished as CAT, otherwise, is ME.
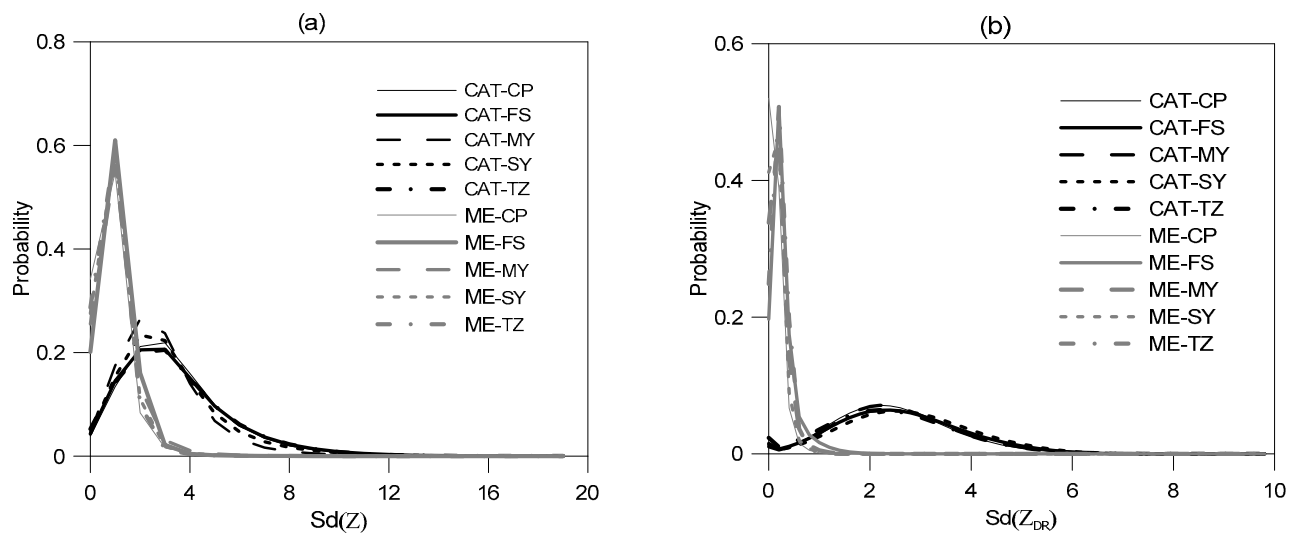

Figure 3. Cont. 

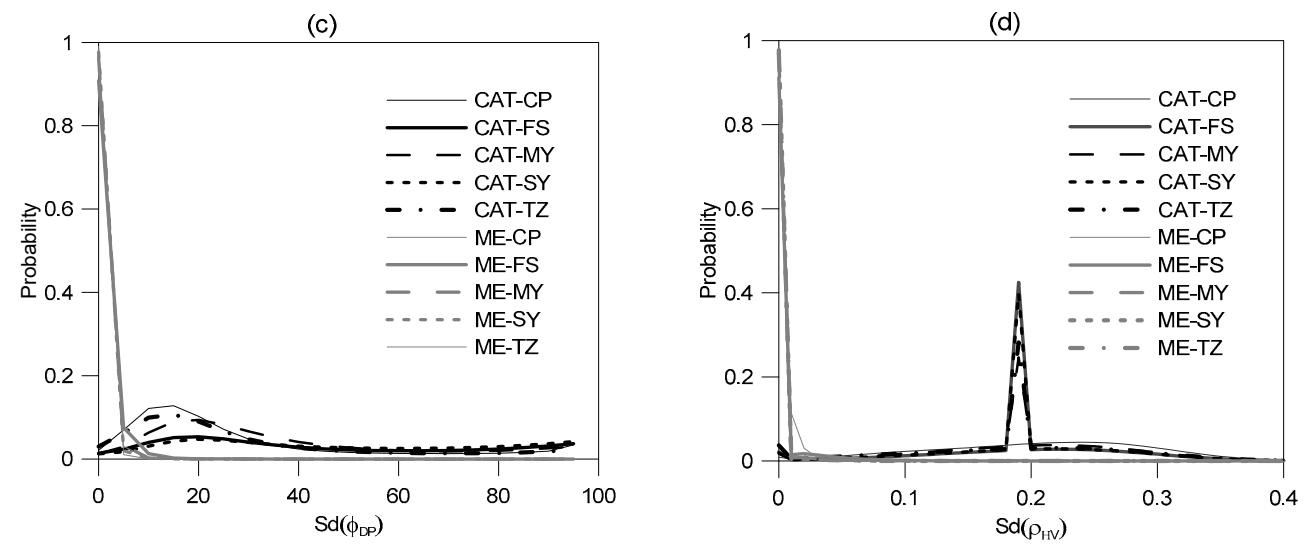

Figure 3. Probability density distribution of parameters (a) $\mathrm{Sd}(\mathrm{Z})$, and, (b) $\mathrm{Sd}\left(\mathrm{Z}_{\mathrm{DR}}\right),(\mathbf{c}) \mathrm{Sd}\left(\rho_{\mathrm{HV}}\right)$, and (d) $\operatorname{Sd}\left(\Phi_{\mathrm{DP}}\right)$ for ME and CAT.

\subsubsection{Evaluation Metrics}

The Bayesian method for recognition and elimination of CAT is evaluated using 44 rainfall events in 2019 and 43 rainfall events from January to September 2020. Akin to the method of Huang et al. [16], the occurrence frequencies of different radar echo types that appear in each range bin are counted as follows:

$$
P(A z, \operatorname{Bin})=\frac{N(A z, \operatorname{Bin})}{T}
$$

where $N(A z, B i n)$ indicates the number of range bins with non-null values at the azimuth $(A z)$, and $T$ is the total number of radar scans. Here, $P$ is expressed in $\mathrm{dB}$ :

$$
\mathrm{dB} P=10 \log _{10} \frac{P}{10^{-5}}
$$

Four different statistics were employed: the occurrence frequency of reflectivity after removing the ground clutter $\mathrm{dB} P_{Z}$, the occurrence frequencies of $\mathrm{CAT} \mathrm{dB} P_{\mathrm{CAT}}$, meteorology echo (ME) $\mathrm{dB} P_{\mathrm{ME}}$, and the ratio of the number of range bins of reflectivity to the total numbers of ME $\mathrm{dB} P_{\mathrm{MEZ}}$.

\section{Results}

\subsection{Verification by a Case Study}

Figure 4 shows the $\mathrm{PPI}_{\mathrm{S}}$ at $1.5^{\circ}$ elevation angle for reflectivity $\left(\mathrm{Z}_{\mathrm{H}}\right)$, differential reflectivity $\left(Z_{\mathrm{DR}}\right)$, the correlation coefficient $\left(\rho_{\mathrm{HV}}\right)$, and propagation phase shift $\left(\Phi_{\mathrm{DP}}\right)$. As shown in Figure 4, a strong clear air signal is prevalent between $90^{\circ}$ and $330^{\circ}$ within $30 \mathrm{~km}$ from the radar (range rings are at $15 \mathrm{~km}$ intervals). The correlation coefficient $\rho_{\mathrm{HV}}$ in this region is relatively small with values between 0.4 and 0.97 , and the proportion less than 0.9 accounts for more than $82 \%$. The fluctuations of $Z_{\mathrm{DR}}$ and $\Phi_{\mathrm{DP}}$ are large. $Z_{\mathrm{DR}}$ and $\Phi_{\mathrm{DP}}$ mainly fluctuate $-6 \mathrm{~dB}-6 \mathrm{~dB}$ and $40^{\circ}-160^{\circ}$, respectively. In addition, the texture distribution of each polarization parameter shows that there is a concentration area of CAT echo within the range of $15 \mathrm{~km}$ from radar (Figure 5). 
(a)

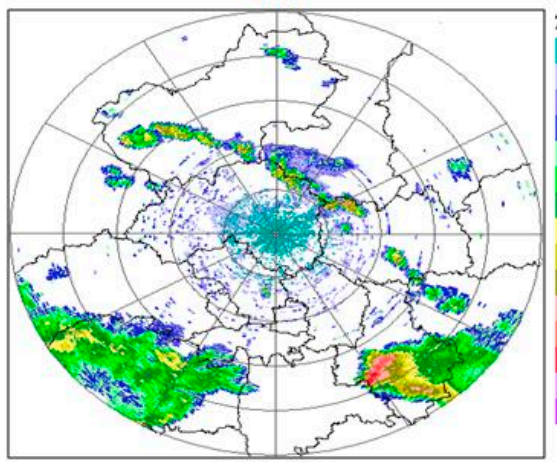

(c)

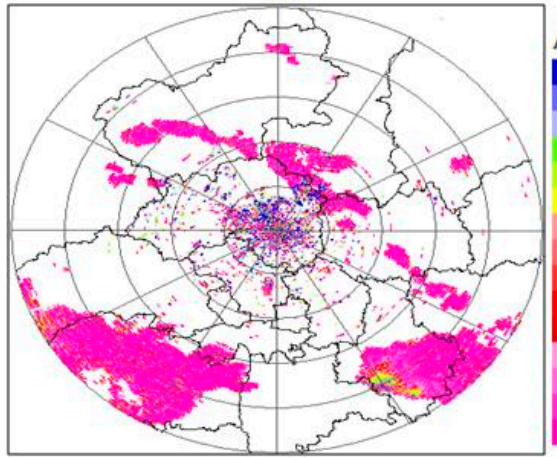

(b)
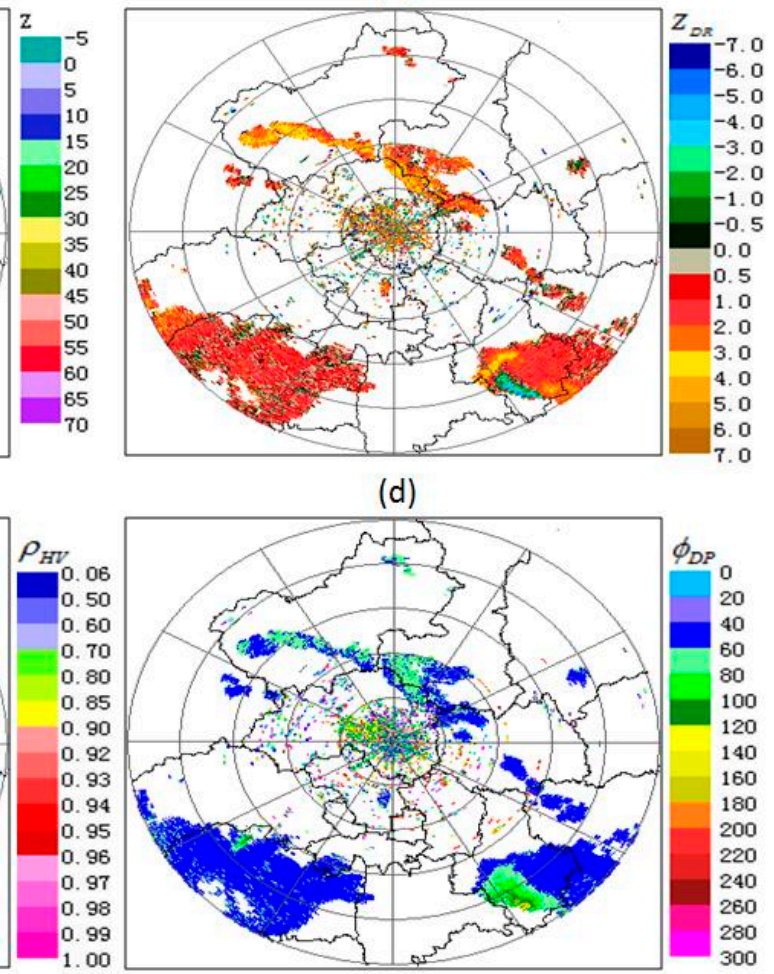

(d)

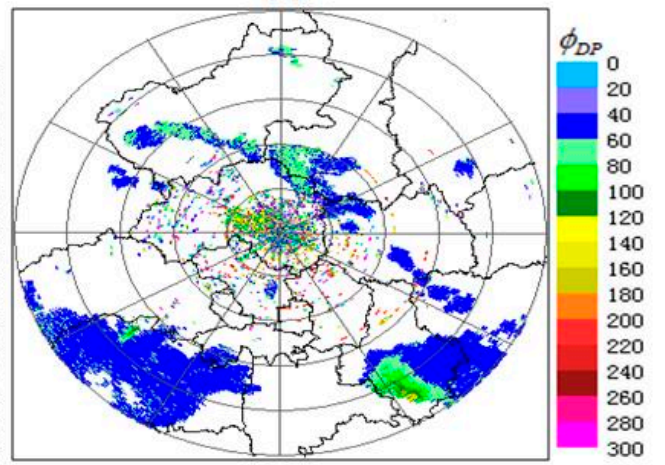

Figure 4. The parameters of (a) $\mathrm{Z},(\mathbf{b}) \mathrm{Z}_{\mathrm{DR}}$, (c) $\rho_{\mathrm{HV}}$, (d) $\Phi_{\mathrm{DP}}$ from Changping radar, $1.5^{\circ} \mathrm{PPIs}$, at 08:00 (UTC) 2 July 2019.

(a)

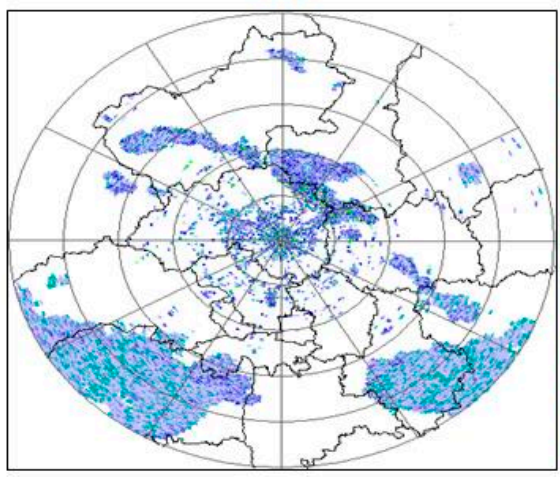

(c)

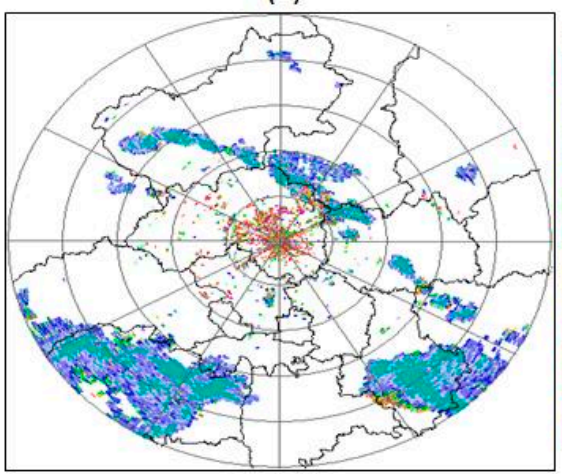

(b)
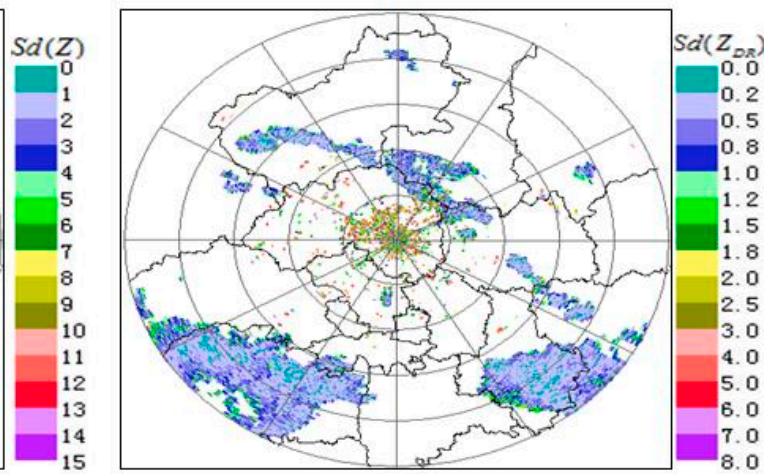

(d)

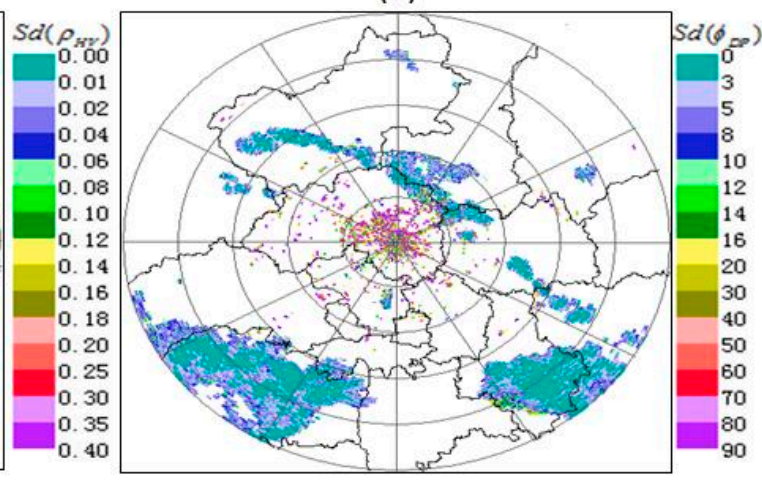

Figure 5. As Figure 4, but for (a) $\operatorname{Sd}(Z),\left(\right.$ b) $\operatorname{Sd}\left(Z_{\mathrm{DR}}\right),(\mathbf{c}) \operatorname{Sd}\left(\rho_{\mathrm{HV}}\right)$, and (d) $\operatorname{Sd}\left(\Phi_{\mathrm{DP}}\right)$. 
Figure 6 shows the variation of $\operatorname{Sd}(Z), \operatorname{Sd}\left(Z_{\mathrm{DR}}\right), \operatorname{Sd}\left(\rho_{\mathrm{HV}}\right)$, and $\mathrm{Sd}\left(\Phi_{\mathrm{DP}}\right)$ of $C A T s$ versus reflectivity $Z$. The reflectivity $Z$ of $C A T$ varies from $-25 \mathrm{dBZ}$ to $30 \mathrm{dBZ}$, and $S d(Z)$ is ranging $0-16 \mathrm{~dB}$. Therein, the proportions of $\mathrm{Sd}(\mathrm{Z})>2 \mathrm{dBZ}, \mathrm{Sd}\left(Z_{\mathrm{DR}}\right)>0.5 \mathrm{~dB}, \mathrm{Sd}\left(\rho_{\mathrm{HV}}\right)>0.05$ and $\operatorname{Sd}\left(\Phi_{\mathrm{DP}}\right)>5^{\circ}$ are $69.8 \%, 97.1 \%, 93.5 \%$ and $97.2 \%$, respectively. The textures of the four parameters (Figure 6) indicate that the characteristics of CATs, that is the fluctuation range of texture is larger than that of meteorological echo, according to the probability density distribution $\operatorname{Sd}(Z), \operatorname{Sd}\left(Z_{\mathrm{DR}}\right), \operatorname{Sd}\left(\rho_{\mathrm{HV}}\right)$, and $\mathrm{Sd}\left(\Phi_{\mathrm{DP}}\right)$ of $\mathrm{ME}$ and $\mathrm{CAT}$ in Figure 3.

(a)

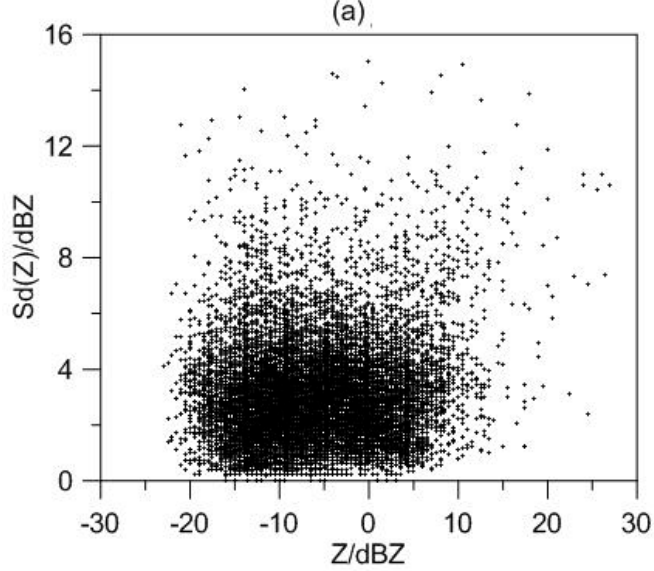

(c)

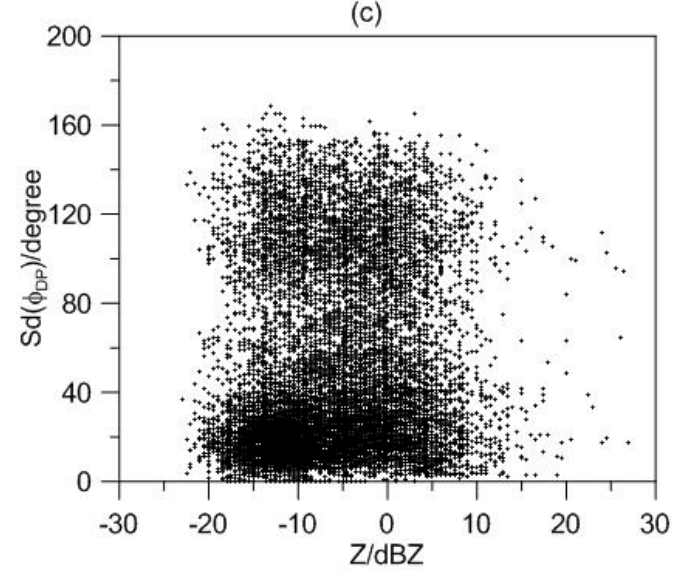

(b)

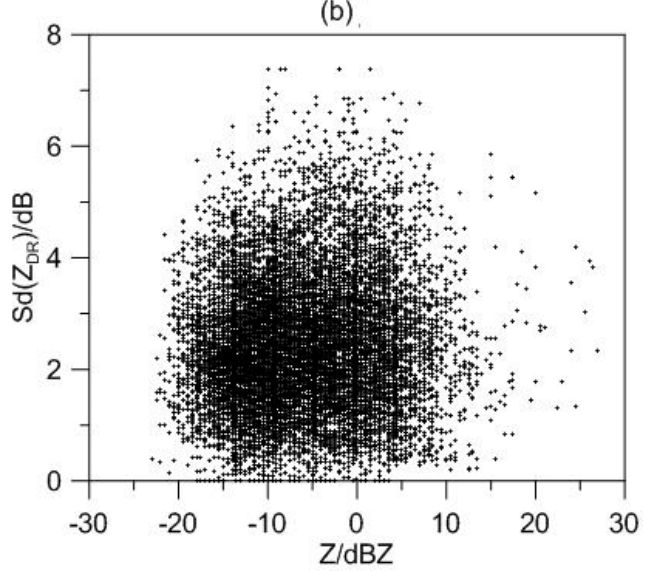

(d)

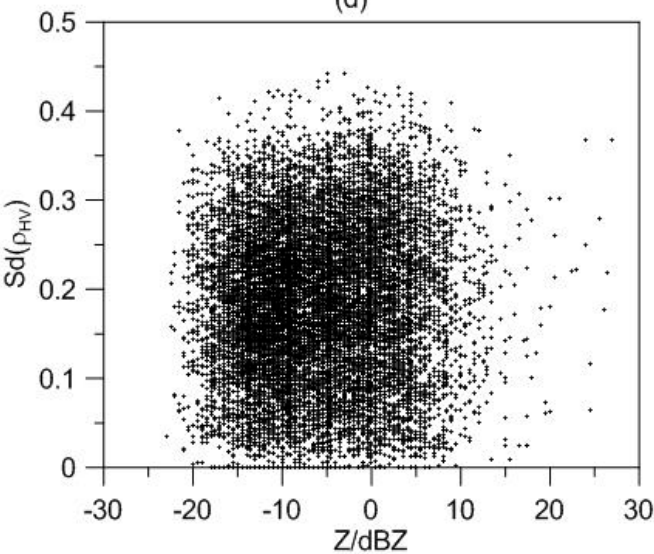

Figure 6. Scatterplots of (a) $\operatorname{Sd}(Z),(\mathbf{b}) \operatorname{Sd}\left(Z_{\mathrm{DR}}\right),(\mathbf{c}) \operatorname{Sd}\left(\Phi_{\mathrm{DP}}\right)$, and (d) $\operatorname{Sd}\left(\rho_{\mathrm{HV}}\right)$ versus $\mathrm{Z}$ for CAT from Changping radar, 1.5 PPI, at 08:00 UTC 2 July 2019.

Figure 7 shows the comparison of reflectivity from raw data and after CAT echo filtering at 08:00 (UTC) 2 July 2019. The CAT echo in the $15 \mathrm{~km}$ range of Changping radar has been removed, and there are 257 range bins left, accounting for only $1.8 \%$ of the total bins of radar echoes, and as high as $98.2 \%$ of the CAT echoes has been eliminated, indicating that the Bayesian method is effective in identifying CAT echoes. 
(a)

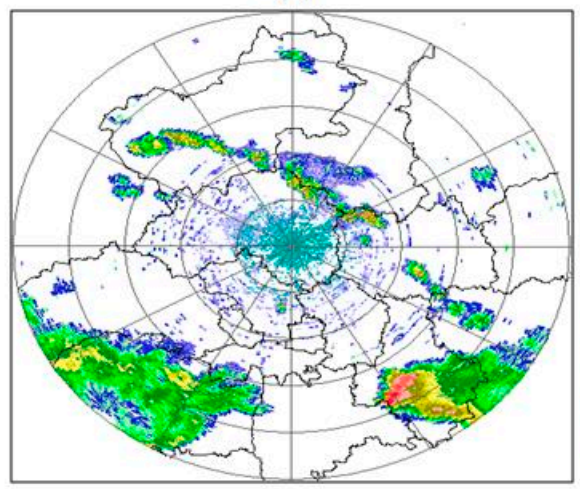

(b)

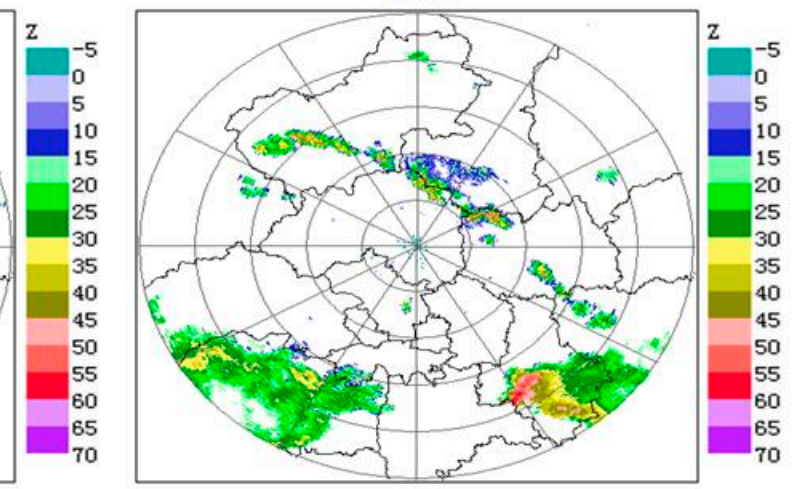

Figure 7. PPI displays of raw reflectivity $\mathrm{Z}_{\mathrm{H}}(\mathbf{a})$ and CAT-removed $\mathrm{Z}_{\mathrm{H}}(\mathbf{b})$ using the Bayesian method from Changping radar at $1.5^{\circ}$ elevation angle at 08:00 (UTC) 2 July 2019.

\subsection{Performance of the Bayesian Method}

Figure 8 displays four statistics $\mathrm{dBP}_{\mathrm{CAT}}, \mathrm{dBP}_{\mathrm{ME}}, \mathrm{dBP}_{\mathrm{Z}}$, and $\mathrm{dBP}_{\mathrm{MEZ}}$ of five radar observations from 44 precipitation events observed from January to December 2019 and 43 precipitation events from January to September 2020. Figure 9 shows the occurrence frequency of azimuthal averaging of four statistics over 360 azimuths versus range. P1-P4 indicate the azimuthal averaging of $\mathrm{dBPCAT}, \mathrm{dBPME}, \mathrm{dBPZ}$, and $\mathrm{dBPMEZ}$, respectively. The CAT echoes of the five radars are mainly concentrated in the $15 \mathrm{~km}$ range of the radar site and gradually decrease with the increase of radial distance (Figure 8(a1)-(e1)). Similar results are obtained from P1 in Figure 9. The proportion of CAT for each radar reaches its peak at around $1 \mathrm{~km}$, therein, peak ratio is as high as $93.9 \%$ for Fangshan radar. With the increase of distance, the proportion of CAT decreases gradually. The proportion of CAT for each radar is very small close to $75 \mathrm{~km}$. There are about $0.9 \%, 1.5 \%, 1.2 \%, 1.2 \%$, and $0.9 \%$ of CAT echoes for Changping radar, Fangshan radar, Miyun radar, Shunyi Radar, and Tongzhou radar, respectively.

After the CAT echoes are removed using the Bayesian method, it can be seen from Figure 8(a2)-(e2) that the CAT echoes with reflectivity greater than $40 \mathrm{~dB}$ within the radar $15 \mathrm{~km}$ range are significantly reduced. In addition, the azimuthal averaging of $\mathrm{dBP}_{\mathrm{ME}}(\mathrm{P} 2$ in Figure 9) showes that the ME ehoes within $15 \mathrm{~km}$ is close to the area outside $15 \mathrm{~km}$, and the distribution is much smoother and not steep as P1. P3 of each radar decreases gradually from the peak. After the CAT echoes were removed, P2 of each radar is less than $16 \%$. In the areas with range exceeding $30 \mathrm{~km}$ where CAT echoes are less frequent, P2 and P3 tend to be consistent with the increase of distance. The proportions of ME to the total echoes are very high $(>49.2 \mathrm{~dB}$ ) (Figure $8(\mathrm{a} 4)-(\mathrm{e} 4))$. The distribution of $\mathrm{P} 4$ for each radar in Figure 9 is greater than $85 \%$, therein, a higher value of more than $90 \%$ appeared from Changping radar, indicating that that the proportion of ME identified as CAT is small. 
(a1)

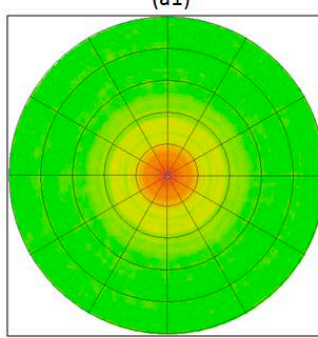

(b1)

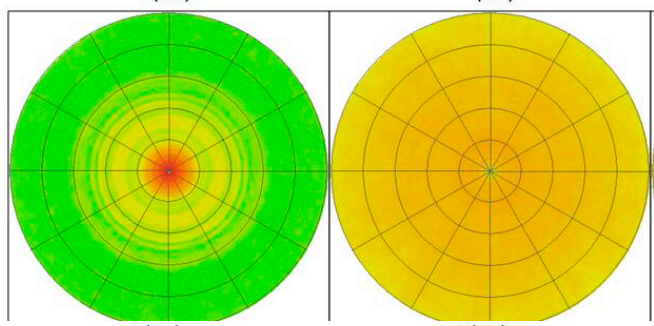

(c1)

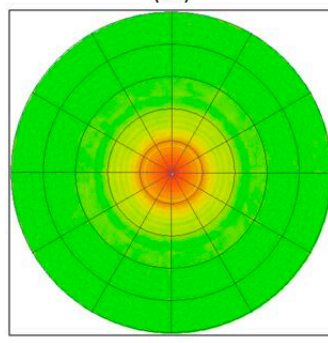

(d1)

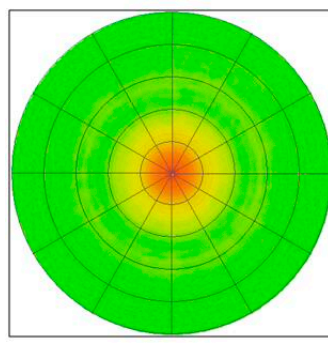

(e1)
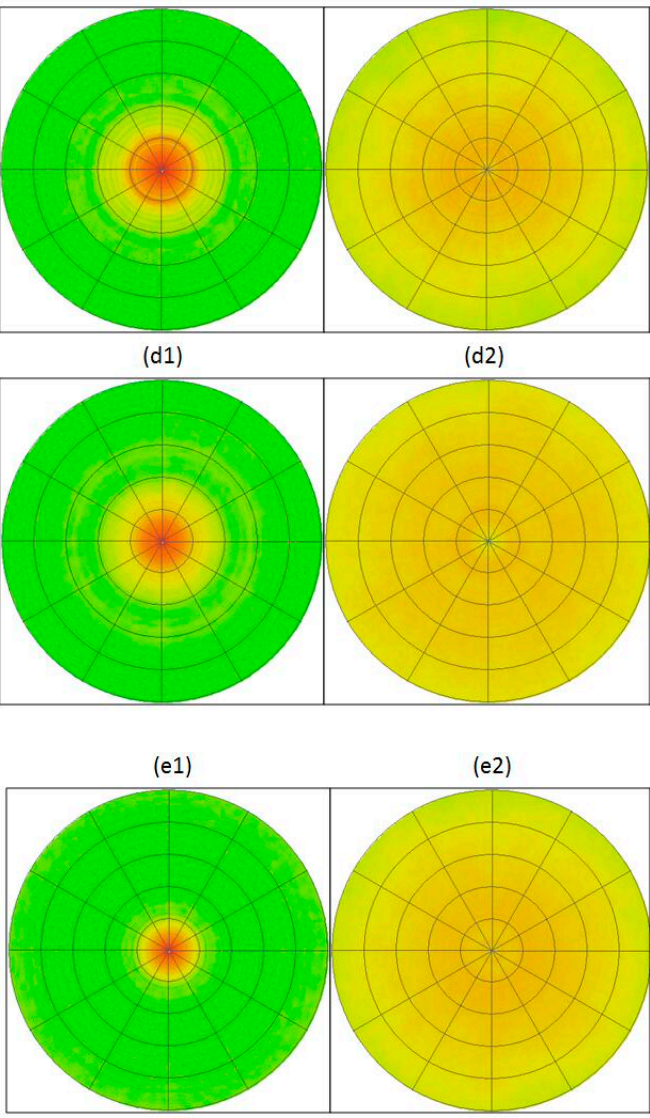

(a2)

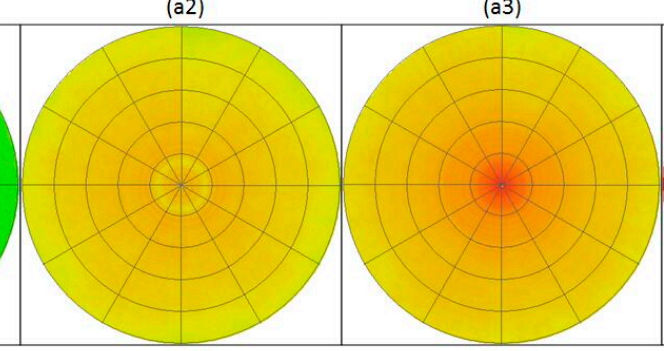

(b3)

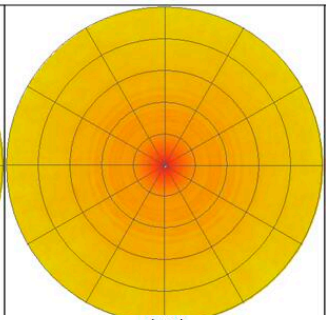

(c3)

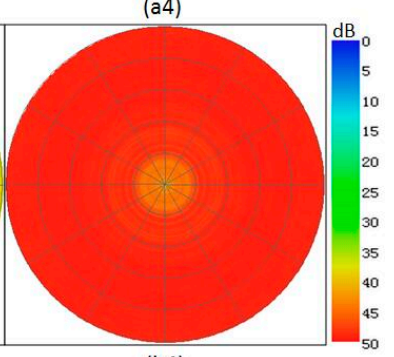

(b4)

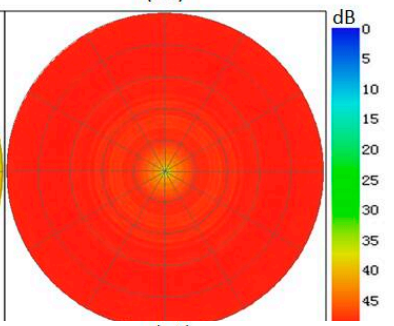

(c4)
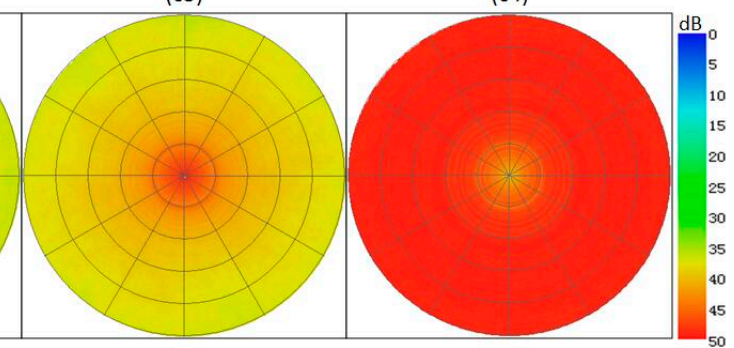

(d3)

(d4)

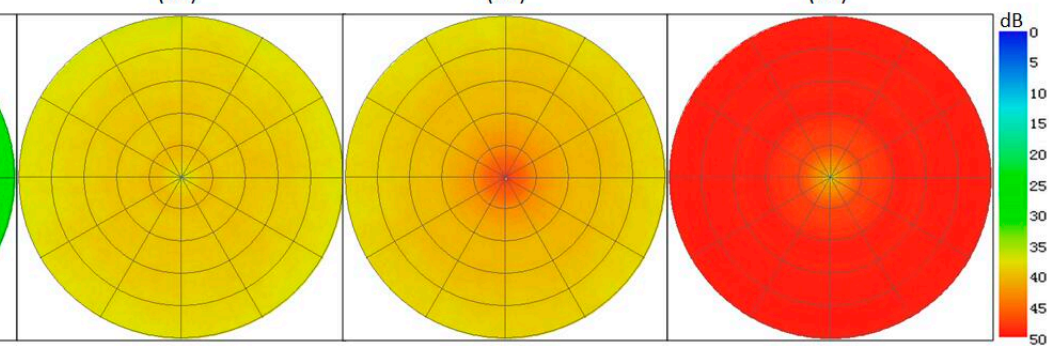

(e3)

(e4)

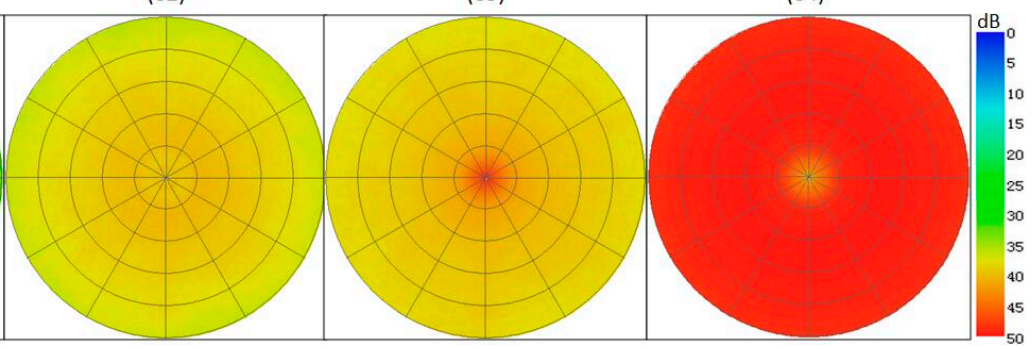

Figure 8. The statistical results of $\mathrm{dBP}_{\mathrm{CAT}}$ (the first column), $\mathrm{dBP}_{\mathrm{ME}}$ (the second column), $\mathrm{dBP}_{\mathrm{Z}}$ (the third column), and $\mathrm{dBP}_{\mathrm{MEZ}}$ (the fourth column) for Changping radar (a1-a4), Fangshan radar (b1-b4), Miyun radar (c1-c4), and Shunyi radar (d1-d4), Tongzhou radar (e1-e4), respectively. 
(a)

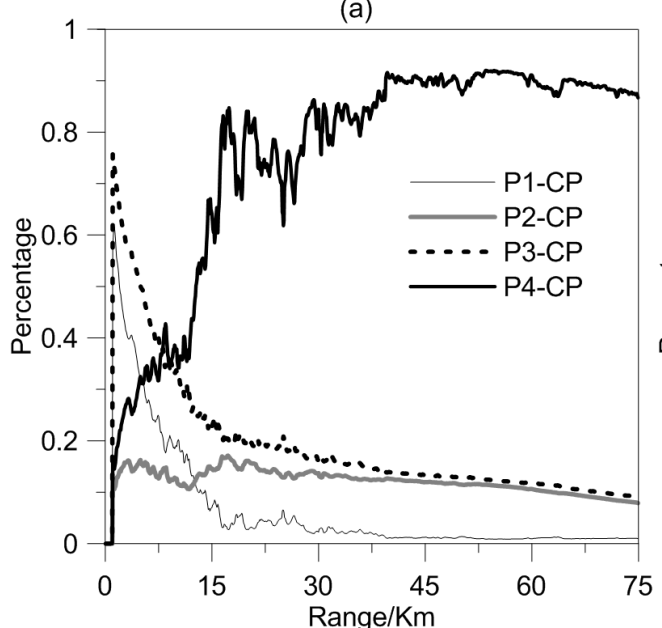

(c)
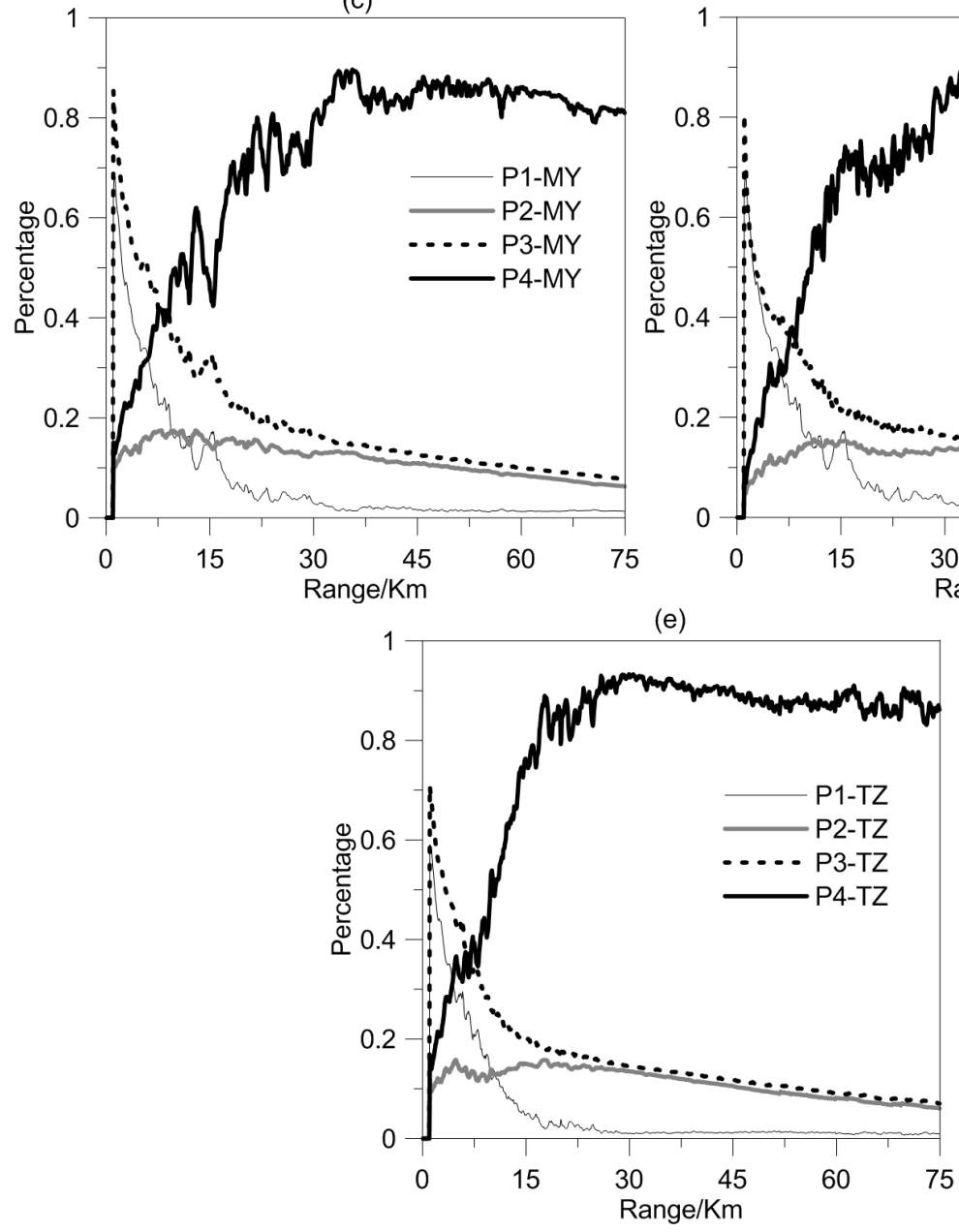

(b)

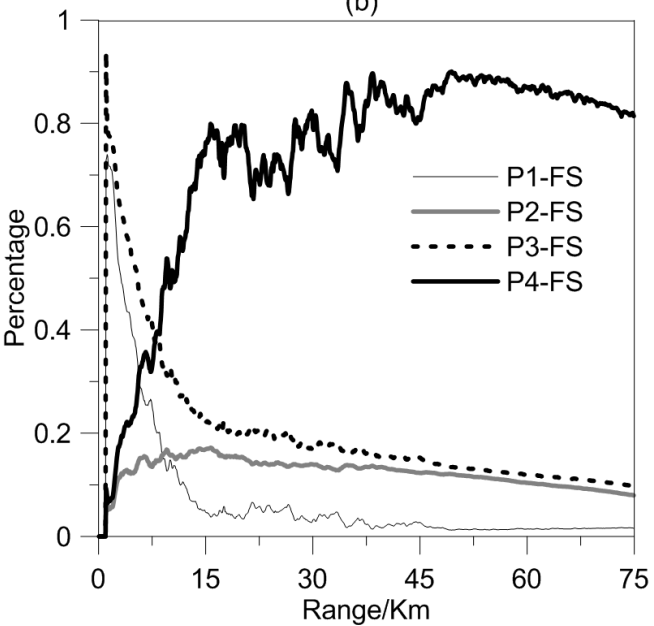

(d)

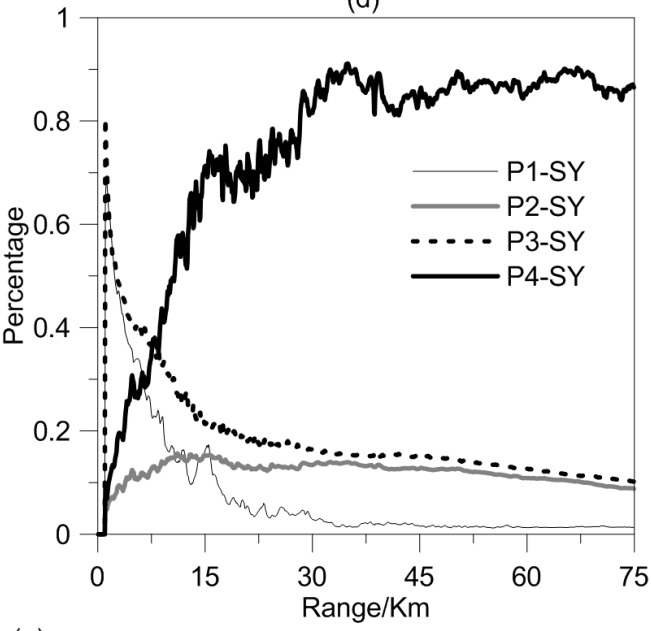

Range/Km 
five parameters in Figure 4, the membership functions of five parameters can be obtained (Figure 10).

(a)

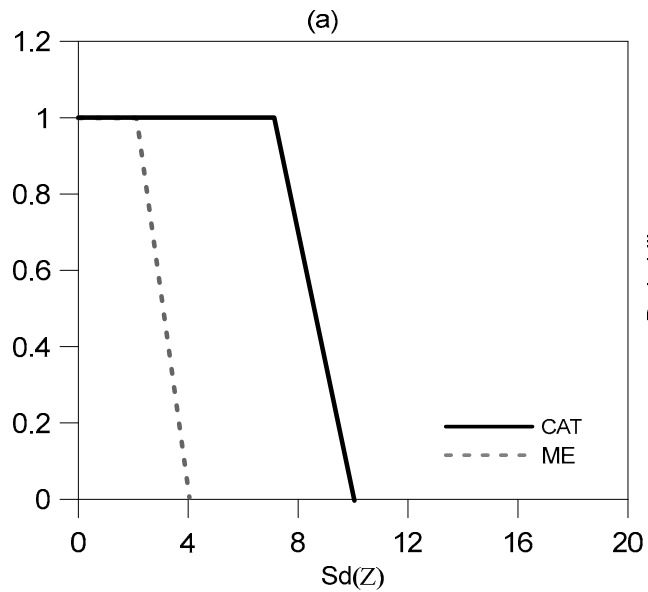

(c)

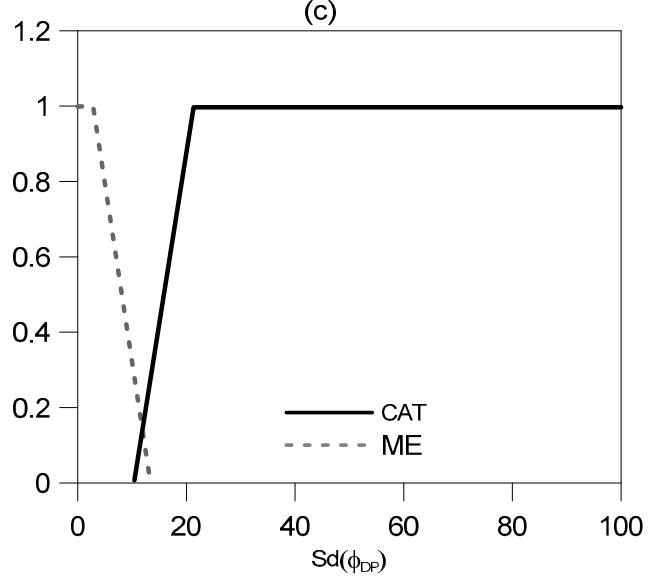

(b)

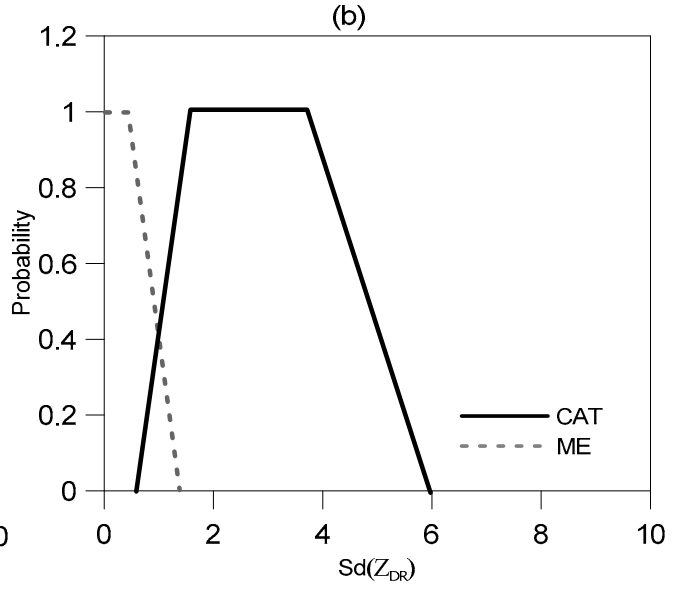

(d)

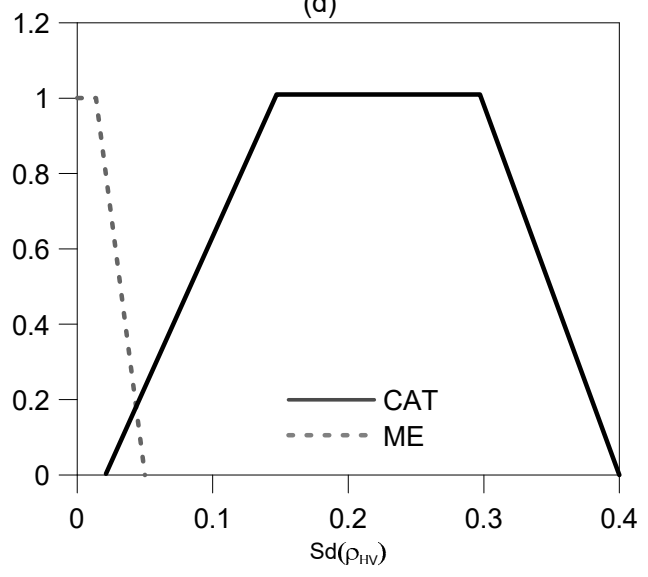

(e)

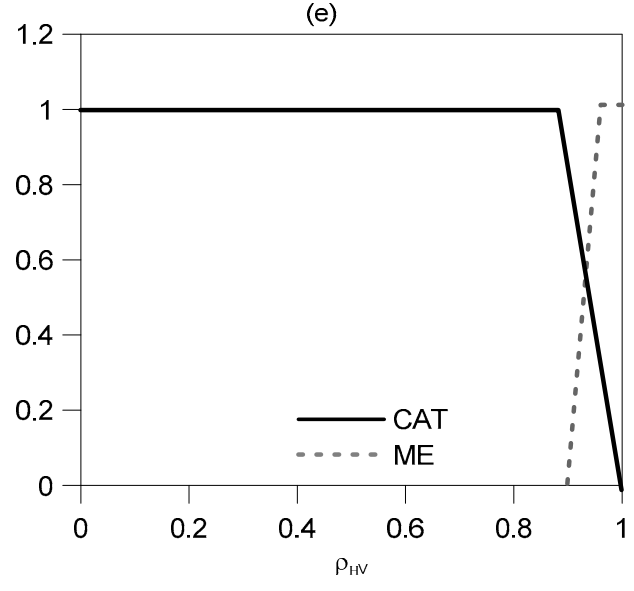

Figure 10. Membership functions of CAT and ME for (a) $\operatorname{Sd}(\mathrm{Z}),(\mathbf{b}) \operatorname{Sd}\left(\mathrm{Z}_{\mathrm{DR}}\right),(\mathbf{c}) \operatorname{Sd}\left(\Phi_{\mathrm{DP}}\right),(\mathbf{d}) \operatorname{Sd}\left(\rho_{\mathrm{HV}}\right)$, and $(\mathbf{e}) \rho_{\mathrm{HV}}$.

In this paper, the data of five Beijing radars at 04:00 (UTC) on 28 May 2018 are selected, and the effects of fuzzy logic and Bayesian methods on the elimination of CAT echoes are compared. After preprocessing the radar data, the total radar echo distance database is recorded as $\mathrm{N}$, the remaining range library is identified and eliminated by the Bayesian method as $\mathrm{N}_{\mathrm{b}}$, and the elimination rate is $\mathrm{P}_{\mathrm{b}}=\left(\mathrm{N}-\mathrm{N}_{\mathrm{b}}\right) / \mathrm{N}$. The number of distance libraries left after fuzzy logic recognition is eliminated is marked as $\mathrm{N}_{\mathrm{f}}$, and the elimination 
rate is $\mathrm{P}_{\mathrm{f}}=\left(\mathrm{N}-\mathrm{N}_{\mathrm{f}}\right) / \mathrm{N}$. The comparison of the two methods is shown in Table 2. After using the Bayesian method to identify and eliminate CAT echoes, the number of radar bins with CAT echoes is significantly reduced. Overall, the recognition and elimination rate of CAT is more than $98.4 \%$. The CAT echo identified and eliminated by the fuzzy logic method is slightly lower, indicating that the Bayesian method is better than the fuzzy logic method.

Table 2. The effect of CAT echo recognition and elimination.

\begin{tabular}{cccccc}
\hline Radars & $\mathbf{N}$ & $\mathbf{N}_{\mathbf{b}}$ & $\mathbf{N}_{\mathbf{f}}$ & $\mathbf{P}_{\mathbf{b}}$ & $\mathbf{P}_{\mathbf{f}}$ \\
\hline Changping & 33612 & 373 & 977 & $98.8 \%$ & $97.1 \%$ \\
Fangshan & 21856 & 143 & 494 & $99.3 \%$ & $97.7 \%$ \\
Miyun & 26344 & 213 & 624 & $99.1 \%$ & $97.6 \%$ \\
Shunyi & 27239 & 151 & 601 & $99.4 \%$ & $97.8 \%$ \\
Tongzhou & 14335 & 224 & 605 & $98.4 \%$ & $95.8 \%$ \\
\hline
\end{tabular}

Figure 11 shows the $1 \mathrm{~km}$ constant altitude PPI (CAPPI) of the radar network from the five radars after using the Bayesian method to identify and eliminate the CAT echoes. It is further filtered out all the clear air turbulence echoes after removing the isolated echo.

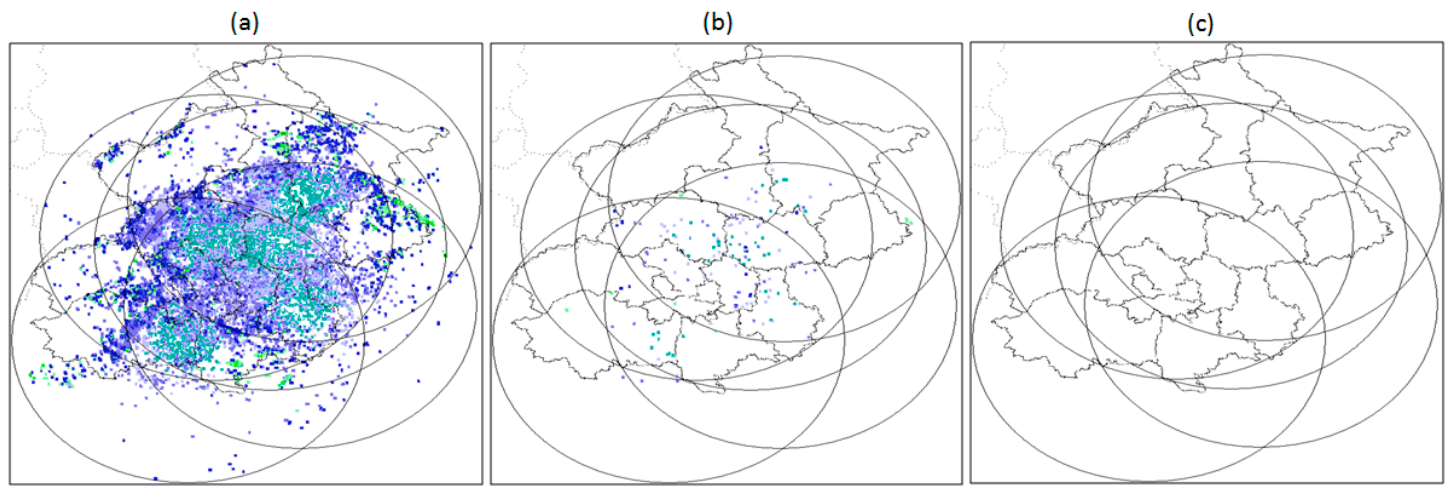

Figure 11. (a) CAT echoes from the five radars, the (b) CAT-removed echoes using the Bayesian method, and (c) the isolated echo filtered after Bayesian method.

\section{Summary and Conclusions}

In this study, a Bayesian method to classify the CAT echoes was developed and tested using radar data from five $\mathrm{X}$-band dual-polarization radars in Beijing. A rainfall case and 87 rainfall events were used to verify and evaluate the performance of the Bayesian method. The main conclusions are as follows:

(1) The characteristics of CATs observed by the Beijing X-band polarimetric radar show that the high-frequency concentration area of turbulent echoes is within $15 \mathrm{~km}$ from radar. The P3 value of the total echo proportion of each range database is high. After the elimination of non-meteorological echoes, the P2 value of ME proportion is maintained within $16 \%$, indicating that the filtering method of CAT echoes is good.

(2) The Bayesian method can filter the edge of MEs with SNR $<15 \mathrm{~dB}$. When the SNR of ME is $<15 \mathrm{~dB}$, the values of $\mathrm{Sd}(\mathrm{Z}), \mathrm{Sd}\left(\mathrm{Z}_{\mathrm{DR}}\right), \mathrm{Sd}\left(\rho_{\mathrm{HV}}\right)$, and $\mathrm{Sd}\left(\Phi_{\mathrm{DP}}\right)$ are higher, causing it to filter out as a CAT.

(3) Compared to traditional fuzzy-logic classification, the Performance of the Bayesian approach is slightly better in identifying the CATs.

Author Contributions: Conceptualization, J.M.; methodology, J.M.; formal analysis, L.L.; resources, M.C.; data curation, S.L.; writing-original draft preparation, J.M.; writing-review and editing, L.L.; project administration, M.C.; visualization, J.M. and S.L. All authors have read and agreed to the published version of the manuscript. 
Funding: This research was funded by the National Key R\&D Program of China (grant: 2018YFF 0300102), the Beijing Municipal Science and Technology Project (grant: Z171100004417008), and the National Natural Science Foundation of China (grant: 42005109).

Institutional Review Board Statement: Not applicable.

Informed Consent Statement: Not applicable.

Data Availability Statement: Not applicable.

Conflicts of Interest: The authors declare no conflict of interest.

\section{References}

1. Anagnostou, M.N.; Kalogiros, J.; Anagnostou, E.N.; Tarolli, M.; Papadopoulos, A.; Borga, M. Performance evaluation of highresolution rainfall estimation by X-band dual-polarization radar for flash flood applications in mountainous basins. J. Hydrol. 2010, 394, 4-16. [CrossRef]

2. Park, S.G.; Bringi, V.N.; Chandrasekar, V.; Maki, M.; Iwanami, K. Correction of Radar Reflectivity and Differential Reflectivity for Rain Attenuation at X Band. Part I: Theoretical and Empirical Basis. J. Atmos. Ocean. Technol. 2005, 22, 1621-1632. [CrossRef]

3. Chen, H.; Chandrasekar, V.; Philips, B. Principles of High-Resolution Radar Network for Hazard Mitigation and Disaster Management in an Urban Environment. J. Meteorolog. Soc. Jpn. 2018, 96A, 119-139. [CrossRef]

4. Fritts, D.C.; Franke, P.M.; Wan, K.; Lund, T.; Werne, J. Computation of clear-air radar backscatter from numerical simulations of turbulence: 2. Backscatter moments throughout the lifecycle of a Kelvin-Helmholtz instability. J. Geophys. Res. Atmos. 2011, 116, D11105. [CrossRef]

5. Oue, M.; Uyeda, H.; Ohigashi, T.; Kouketsu, T.; Mizutani, F. Airflow Structure of Clear-Air and Precipitation Echoes Observed by an X-band Doppler Radar over the Nobi Plain in Japan in the Summer of 2010. In Proceedings of the Conference on Radar Meteorology, Pittsburgh, PA, USA, 26-30 September 2011.

6. Takeda, T.; Murabayashi, S. Observation of Clear-Air Echoes with 3.2-cm Radars. J. Meteor. Soc. Japan 1981, 59, 864-875. [CrossRef]

7. Larkin, R.P. Flight speeds observed with radar, a correction: Slow "birds" are insects. Behav. Ecol. Sociobiol. 1991, 29, 221-224. [CrossRef]

8. Luke, E.P.; Kollias, P.; Johnson, K.L.; Clothiaux, E.E. A Technique for the Automatic Detection of Insect Clutter in Cloud Radar Returns. J. Atmos. Oceanic Technol. 2008, 25, 1498-1513. [CrossRef]

9. Liu, X.D. Summary on Applications of Stratiform Clear Air Echo in Nowcasting. Meteorol. Environ. Res. 2010, 1, 101-106.

10. Chang, P.-L.; Wang, B.-S.; Shieh, S.-L.; Jou, B.J.-D. Clear-air echo statistics and beam blockage patterns of Taiwan Doppler radar network. In Proceedings of the 31st International Conference on Radar Meteorology, Seattle, WA, USA, 8 August 2003.

11. Abernethy, J.; Sharman, R.; Bradley, E. An Artificial Intelligence Approach to Operational Aviation Turbulence Forecasting. In Proceedings of the Thire International Conference On Research in Air Transportation, Farfax, VA, USA, 1-4 June 2008.

12. Williams, J.K. Detection and Nowcasting of Convective Turbulence Using Artificial Intelligence Techniques. In Proceedings of the 93rd American Meteorological Society Annual Meeting, Austin, TX, USA, 9 January 2013.

13. Rico-Ramirez, M.A.; Cluckie, I.D. Classification of ground clutter and anomalous propagation using dual-polarization weather radar. IEEE Trans. Geosci. Remote Sens. 2008, 46, 1892-1904. [CrossRef]

14. Lakshmanan, V.; Zhang, J.; Howard, K. A Technique to Censor Biological Echoes in Radar Reflectivity Data. J. Appl. Meteorol. Climatol. 2010, 49, 453-462. [CrossRef]

15. Papoulis, A.; Pillai, S.U. Probability, Random Variables and Stochastic Processes, 4th ed.; McGraw-Hill: New York, NY, USA, 1991.

16. Huang, X.y.; LI, Y.; Zhang, S.; Huang, S.; Wei, K. The algorithm and verification of ground clutter identification based on fuzzy logic. J. Trop. Meteorol. 2018, 34, 305-313. (In Chinese) 